\title{
PReS-FINAL-2160: Intestinal microbiome in polyarticular juvenile idiopathic arthritis: a pilot study
}

\author{
PC Hissink Muller ${ }^{1,2^{*}}$, PM Westedt ${ }^{2}$, AE Budding ${ }^{3}$, CF Allaart ${ }^{4}$, DM Brinkman ${ }^{2,5}$, TW Kuijpers ${ }^{6}$, JM Van den Berg ${ }^{6}$, \\ LW Van Suijlekom-Smit ${ }^{7}$, MA Van Rossum ${ }^{6,8}$, TG De Meij ${ }^{9}$, R Ten Cate $^{2}$
}

From 20th Pediatric Rheumatology European Society (PReS) Congress

Ljubljana, Slovenia. 25-29 September 2013

\section{Introduction}

The intestinal microbiome may play a role in the pathogenesis of Juvenile Idiopathic Arthritis (JIA). In IBD patients an overall decrease in microbial diversity of the intestinal microbiota has been observed. Studies comparing intestinal microbiome in children with JIA and healthy controls have not been conducted to date.

\section{Objectives}

To analyse and compare the composition and diversity of the distal colon associated microbiome between children with Disease-Modyfying-Anti-Rheumatic-Drug (DMARD) naive JIA and healthy controls and to identify specific gut bacteria associated with JIA before initiation of a DMARD.

\section{Methods}

Total microbiome profile in stools of 8 children with DMARD naive polyarticular JIA were analyzed by means of IS-pro, a 16S-23S interspacer (IS) region-based profiling method and compared to stools of 24 age-matched healthy controls.

\section{Results}

Faeces of 8 ( 6 girls, 2 boys) children with polyarticular JIA, all rheumatoid factor negative were investigated and compared to 24 healthy controls. Anti-Nuclear Antibodies were positive in 3 patients. Median age at evaluation was 11.1 years (7.3-13.1), median period from start complaints to diagnosis was 7.1 months (4.4-13.2). Median ACR pedi scores were: VAS physician $47 \mathrm{~mm}(32-58)$, VAS patient well-being $32 \mathrm{~mm}(27-52)$, ESR $8 \mathrm{~mm}(2-9)$, active joint count 10(7-14), limited joint count $2(0-4)$, CHAQ score $1.2(0.4-1.7)$.

One intra-articular steroid injection was given to each of two patients respectively 1 and 4 months prior to stool collection. Non Steroidal antiinflammatory Drugs (nsaids) were used by all patients at the time of evaluation. Median age of the healthy controls was 10.6 years (8.4-12.9).

The median Simpsons' diversity index within the phylum Firmicutes in controls and JIA was 0,88 , and 0,83 respectively $(\mathrm{p}<0,012)$. Diversity within the phyla Bacteriodetes and Proteobacteria did not differ between the 2 subgroups. By constructing a Pearson-correlation dendogram, no clustering was seen between the JIA group and the healthy controls on species-level (figure 2), a specific JIA associated microbiotal signature could not be identified.

\section{Conclusion}

Intestinal microbiome diversity within the phylum Firmicutes was significantly lower between children with DMARD naive polyarticular JIA and healthy controls. An overall decrease in microbial diversity of the intestinal microbiota has also been observed in IBD patients. Whether intestinal dysbiosis plays a role in the pathogenesis of JIA remains subject of further studies.

\section{Disclosure of interest}

None declared.

'Pediatric Rheumatology, Reade, location Jan van Breemen, Amsterdam,

Netherlands

Full list of author information is available at the end of the article 


\section{Authors' details}

'Pediatric Rheumatology, Reade, location Jan van Breemen, Amsterdam, Netherlands. ${ }^{2}$ Pediatric Rheumatology, LUMC, Leiden, Netherlands. ${ }^{3}$ Medical Microbiology, VU Medical Center, Amsterdam, Netherlands. ${ }^{4}$ Rheumatology, LUMC, Leiden, Netherlands. ${ }^{5}$ Pediatrics, Rijnland Hospital, Leiderdorp, Netherlands. ${ }^{6}$ Pediatric Rheumatology, Academic Medical Center, Emma Children's Hospital, Amsterdam, Netherlands. 'Pediatric Rheumatology, Erasmus MC, Sophia Children's Hospital, Rotterdam, Netherlands. ${ }^{8}$ Pediatric Rheumatology, Reade location Jan van Breemen, Netherlands. ${ }^{9}$ Pediatric Gastroenterology, VU Medical Center, Amsterdam, Netherlands.

Published: 5 December 2013

doi:10.1186/1546-0096-11-S2-P172

Cite this article as: Hissink Muller et al:: PReS-FINAL-2160: Intestina microbiome in polyarticular juvenile idiopathic arthritis: a pilot study. Pediatric Rheumatology 2013 11(Suppl 2):P172.

\section{Submit your next manuscript to BioMed Central} and take full advantage of:

- Convenient online submission

- Thorough peer review

- No space constraints or color figure charges

- Immediate publication on acceptance

- Inclusion in PubMed, CAS, Scopus and Google Scholar

- Research which is freely available for redistribution

Submit your manuscript at www.biomedcentral.com/submit
C Biomed Central 